\title{
The discursive construction of childhood and youth in AIDS interventions in Lesotho's education sector: beyond global-local dichotomies
}

\section{Nicola Ansell}

In Southern Africa interventions to halt the spread of AIDS and address its social impacts are commonly targeted at young people, in many cases through the education sector. In Lesotho, education sector responses to AIDS are the product of negotiation between a range of 'local' and 'global' actors. While many interventions are put forward as government policy and implemented by teachers in schools, funding is often provided by bilateral and multilateral donors, and the international 'AIDS industry', in the form of UN agencies and international NGOs, sets agendas and makes prescriptions. This paper analyses interviews conducted with policy makers and practitioners in Lesotho, and a variety of documents, critically examining the discourses of childhood and youth that are mobilised in producing changes in education policy and practice to address AIDS. Focusing on bursary schemes, lifeskills education and rights-based approaches, the paper concludes that although dominant 'global' discourses are readily identified, they are not simply imported wholesale from the West, but rather are transformed through the organisations and personnel involved in designing and implementing interventions. Nonetheless, the connections through which these discourses are made, and children are subjectified, are central to the power dynamics of neoliberal globalisation. This although the representations of childhood and youth produced through the interventions are hybrid products of local and global discourses, the power relations underlying them are such that they, often unintentionally, serve $a$ neoliberal agenda by depicting young people as individuals in need of saving; of developing personal autonomy or of exercising individual rights.

Key words: Africa; AIDS; Children; Education; Lesotho; Youth

\section{Introduction}

Initiatives pursued by international agencies, NGOs and donors across the Third World are often deemed Eurocentric in their assumptions. Those focused on young people are said to embody a discursive construction of the 'global child' (Boyden 1990) that does not conform to the ideals of childhood or experiences of children in the societies in which they are implemented. Furthermore, mobilising such discourses, and the policies and programmes they support, is considered potentially damaging to impoverished children (Aitken et al 2006).

In southern Africa, a raft of novel child and youth-focused initiatives have been implemented in response to AIDS. In Lesotho, a small mountainous country, encircled by South Africa, efforts to address the disease focus heavily on children, in part because they are vulnerable to infection: among 15-24 year olds, 5.9\% of men and $14.9 \%$ of women are already infected (UNAIDS 2008). More significantly, children are considered 
a window of opportunity; a group with relatively low infection rates, ' amenable to behaviour change that might alter the course of the pandemic. Initially, therefore, international agencies emphasised prevention of heterosexual transmission to the young. However, AIDS also impacts on children in other ways. By 2003 19\% of 0-17 year olds were orphans, mostly due to AIDS (UNAIDS/UNICEF/USAID 2004). As elsewhere in Africa, many not yet orphaned inhabit households that experience impoverishment when adults are too sick to work and require expensive care and funerals (Ntozi 1997). Children sometimes substitute for adult workers in the home, including as carers for sick relatives (Robson et al 2006), and sometimes outside the home (MOHSW 200I). They may move home to be cared for by other adults, or because their help is required elsewhere (Ansell and van Blerk 2004). Those known to be affected by AIDS may suffer discrimination and stigma (Witter and Were 2004).

Efforts to address the adverse consequences of AIDS for young people have often been channelled through the education system, in part because most children attend school. Since Lesotho introduced Free Primary Education in 2000, the gross enrolment rate has risen to $114 \%$, and gross secondary school enrolment is $37 \%$ (UNESCO 2008). The education system reflects the interests and involvement of many actors. It is likened to a three-legged stool, resting on government (which trains and pays teachers and sets the curriculum), the churches (which own and manage most schools) and communities (which form advisory committees). However, the system is also subject to influences from elsewhere, including overseas. Teaching is strongly driven by the requirements of examinations that (a small minority of) students take at the end of secondary school, which are validated by the University of Cambridge Local Examinations Syndicate. ${ }^{2}$ The sector also depends heavily on donor assistance, especially for non-recurrent spending (Ministry of Education and Training 2005); most initiatives are donor funded, and frequently initiated by NGOs or UN agencies.

The involvement of international actors is particularly prominent in relation to AIDS, for several reasons. AIDS is seen by the international development community and by the Lesotho government as an unprecedented large-scale threat requiring drastic action, with no immediately apparent local (or national) solution, and little indigenous expertise. Furthermore, there is also a high availability of donor funding in this area, from both bilateral donors and specific funding schemes (notably, the US\$10 billion Global Fund and US\$I5 billion President's Emergency Plan for AIDS Relief (PEPFAR)).

This paper critically examines three initiatives that have been deployed through Lesotho's education system to address AIDS and its consequences, exploring how these draw on diverse discourses of childhood and

\footnotetext{
' A significant number of children are infected through mother-to-child transmission, at birth or through breastfeeding (although Lesotho's efforts to prevent these forms of transmission are having an impact). As few of these children live beyond the age of 5 , they are not a prominent concern of the education sector.

2 The fact that this examination board, which sets or regulates school examinations in many former British colonies worldwide, describes itself as 'local' highlights how vexed the terms 'global' and 'local' are in a postcolonial world.
} 
youth, and reflect the interests and ideologies of local ${ }^{3}$ and international actors. It argues that there is a need to move beyond simple binaries of global-local or accusations of Eurocentrism in understanding the unequal transnational exchanges at the root of these interventions. Rather, the representations of childhood and youth that are deployed might be understood as hybrid products, which are nonetheless reflective of highly imbalanced power relations. This paper adopts an approach that is attentive to the spatial organisation of postcolonial power to illuminate how the interventions, while not simple imports from the West, ultimately serve a neoliberal agenda.

The paper begins by contextualising its critique in the growing literature on childhood's discursive construction and the export of global models. Constructs of childhood prevalent in Lesotho are outlined, before the paper considers the three interventions that form its empirical focus: bursary schemes; life skills education; and rights-based approaches. The paper concludes that although dominant 'global' discourses may be identified in each of the three interventions, they are not simply imported wholesale from the West, but rather are transformed through the organisations and personnel involved in their design and implementation. Nonetheless, the transnational connections through which these discourses are made, and children are subjectified, are central to the power dynamics of neoliberal globalisation.

\section{Discourses of childhood}

Three broad discourses of childhood and youth are presented below, two of which are of Western origin, but have strongly informed the attitudes and interventions of international organisations in relation to children globally. These discourses are related to the development of Western capitalism and have been promulgated in the interests of neoliberal globalisation. The third discourse reflects constructions of childhood and youth among the Basotho. This might be described as a 'local' or 'national' discourse, at least insofar as it has not been widely exported beyond the national boundary, although it shares many similarities with 'local' discourses of childhood prevalent elsewhere in southern Africa. This review of literature supports the paper's argument that while the critique of Eurocentrism is important, it does not adequately address the power relations that shape the circulation of discourses of childhood in AIDS interventions.

\section{The 'global model'}

All societies ascribe characteristics to children and youth, many of them unrelated to physical or mental immaturity. In the West, children are viewed as very distinct from adults: as lesser, closer to nature, more innocent and needing protection (Jenks 1996). Western discourses are, however, contradictory and have emerged in response to changing historical circumstances (Heywood 200I). In past centuries, when few infants survived childhood and the doctrine of original sin prevailed, the priority was to discipline inherently

\footnotetext{
${ }^{3}$ The term 'local' is used here to refer to Lesotho-based actors and discourses as opposed to 'global' imports with origins elsewhere. In many cases these are of course 'national' in scope. The scalar constitution and arrangements of the organisations involved in producing AIDS-related interventions in Lesotho schools are discussed elsewhere (Ansell 2009).
} 
sinful children into good behaviour to ensure their redemption (Holloway and Valentine 2000). Fear of the 'polluting' effect of unruly children, along with a concern to produce adults capable of contributing to an industrial economy, informed social policy in Victorian Britain (Boyden 1990), and even today the concern persists that a dysfunctional family may liberate demonic forces inherent in a child (James et al 1998). A contrasting view that children's inherent state is natural, innocent and needs defending is traceable to Rousseau's 18th century writings (James et al 1998), but gained force in the twentieth century as children's economic value was postponed to adulthood, and more resources were available to indulge them. The emergence of industrial capitalism and later neoliberalism, required children to be raised as a disciplined future workforce, rather than direct contributors to the household economy; an expectation that supported the development of compulsory education. A related trend, also associated with the emergence of capitalism, was for children to be seen as in need of, and the responsibility of, nuclear families, and not members of wider society in their own right (Qvortrup 2005).

The consistency of Western discourses of childhood also disperses along lines of class, gender and age. The idealised Western childhood is doubtless most reflective of middle or upper class experience, although working class childhoods have been widely imagined in Western literature, very often as contrasts to the childhood ideal. The childhood (and more so youth) of popular imagination, particularly in terms of proximity to nature, is also normatively male (Jones 1999). Yet girls are classically understood to embody exaggerated characteristics of childhood; to be more vulnerable, more innocent, in greater need of protection, further from rational autonomous adulthood. Moreover, as girls were not (in most places) expected to enter paid employment, there was less concern for their education or moral panic about their control. The significance of age is most apparent as children enter their teenage years. 'Youth' in the twentieth century became seen as a crucial if troubling lifecourse stage; a time of transition from innocent childhood to responsible adulthood, contingent on the right conditions being provided.

Popular discourses of childhood and youth interact with academic theories. The latter are undeniably embedded in the former; the framing of research and theory reflects popular opinions as much as it seeks to challenge them. Throughout much of the twentieth century, academic interest in childhood was dominated by developmental psychology. Piaget (1972) promoted the notion that children (should) develop cognitive competencies in a universal temporal order. This widely accepted hierarchical model assumed progression towards the ultimate goal of adulthood: a rational world view. Presented as universally applicable, the model was exported widely into non-Western contexts. It has, however, been criticised as Eurocentric because children in many societies follow differently timed and sequenced pathways, which by this universalising measure are categorised as 'abnormal' (Burman 1995). The model also assumes the progressive individualisation of each child, which is fundamental to neoliberalism but again conflicts with expectations in many non-Western societies. Other psychologists have departed from Piaget's model. Vygotsky (1933/1967), for instance, posited that children learn to reason through social engagement with 
the immediate environment, and thus context plays a role. Like Piaget's model, however, Vygotsky considered development's ultimate goal to be the production of autonomous rational adults (Caputo 1995).

Beyond the purely cognitive domain, Bowlby (1966/I95I) argued that children under three needed constant contact with their mothers (or 'permanent mother substitute'), to promote the formation of an attachment relationship that he considered crucial to subsequent social and cognitive development. This thesis was popularised by the World Health Organisation and rapidly won support from post-war governments concerned to maximise employment for returning servicemen (Rutter 1972). While undermined by evidence of successful childrearing in many societies in which children form attachments with multiple adults and peers (Smith and Cowie 1988), the expectation that children should follow a trajectory from attachment to detachment remains strong in Western societies (Burman 1995), again reflecting the neoliberal desire for individualised autonomous adults.

Academic studies of adolescence, too, have propagated models assuming Western experience as normative. Again, the expectation of turmoil, attributable to hormonal changes taking place at puberty (Griffin 200I) is refuted by an apparent absence of this stage of 'storm and stress' in other societies (Finn 200I; Mead 1928).

Together these various perspectives with Western roots have, according to Boyden and Ennew (1997), been woven into a 'global model of childhood' that has been exported across the world, particularly through NGO and donor policies. This global model is cast as superior to all other childhoods, and serves, they argue, to delegitimise other childhoods that do not conform, and to cast children as passive victims rather than actors in their own lives (Boyden and Ennew 1997). Clearly an exercise of neo-colonial power, reflecting the global reach of Western society, the export of this global model also reflects the economic inequalities that spatially structure international aid. Moreover, while the emergence of the global model was associated in the West with the development of capitalism, it now arguably supports the export of capitalist neoliberalism to societies in receipt of aid.

\section{Building an alternative global model}

Boyden and Ennew's critique of the global model draws upon another academic approach to childhood that became dominant in the 1990s, alongside a shift in policy discourse expressed in the 1989 UN Convention on the Rights of the Child (UNCRC). The New Social Studies of Childhood (James et al 1998) rested on two propositions: that childhood is a social construct which differs temporally and between and within societies; and that children are social actors. Accepting that worldwide there are 'vastly different understandings of what it is to be young' (Ruddick 2003:357), global discourses of childhood are declared 'dangerous' (Pain 2004) for inspiring the export of policies and practices that falsely assume universal experience, or aspire to globalise a middle-class Western ideal of childhood (Aitken et al 2006). 
Beyond critiquing universalism, the New Social Studies of Childhood set out to produce a new discourse of childhood that empowered children by recognising their agency (Prout and James 1990). This celebration of children's subjecthood and agency was neither a complete departure from earlier sociological perspectives on childhood, nor from popular discourses. Moreover, the 'agency' or 'participation' thread was apparent (alongside provision and protection) in the UNCRC. This convention strongly informs international discourse on children and has shaped law-making in countries worldwide.

The UNCRC has, nonetheless, been accused of Eurocentrism, in part because it enshrines aspects of the 'global model'. Children are represented as in need of protection, and belonging inside the home and nuclear family (Ennew 1995). The needs of children outside these domains (street children, child soldiers, working children) are not addressed. Childhoods not conforming to the Convention, and the actions of carers, are rendered 'abnormal' (Boyden 1990) and their worth undermined (Mayo 200I).

A second critique has a contrasting focus. In affording rights to children, the UNCRC challenges Western discourses that cast children as passive or incompletely human. ${ }^{4}$ Rather it seeks to secure for children the right to participate in decisions: to exercise agency, albeit in a limited field; and this has proven highly controversial. Rights discourse inevitably assumes a universalised abstract subject, independent of economic, cultural and gender differences (Burman 1995). The abstract subject of the UNCRC is arguably a child of Western imagination, raised in a society that values individuality and freedom of expression in ways that many non-Western societies do not (Griesel et al 2002). Many societies view children not as independent bearers of rights but belonging to wider social structures, yet while the Convention refers repeatedly to parents it does not acknowledge extended families and communities (Scheper-Hughes and Sargent 1998). Furthermore, the emphasis in both the UNCRC and the New Social Studies of Childhood on children's autonomy conflicts with developments in the wider social sciences that render claims to autonomous agency problematic (Prout 2005; Holt and Holloway 2006). For Ruddick (2007: 515), 'recent work that figures the child as social actor can be seen as a move towards theorizing the child as a liberal subject'. Discourse is produced by and reflects political and economic materialities (Faria 2008), and the UNCRC is said to inscribe not just a 'thorough-going individualism' (Burman 1996: 58), but neoliberal globalisation (Kjorholt 2007), with the production of individual bearers of rights embedded in nuclear families ultimately functional to global capitalism (Ruddick 2007). Thus, the longstanding epistemological assumption of a polarity in childhood studies between the discursive construction of children and youth as autonomous agents and their construction as innocent and passive disguises the extent to which both discourses have evolved with Western capitalism and served to extend its reach into less prosperous regions of the world.

\footnotetext{
${ }^{4}$ It does not, of course, concede children the same rights as adults; its existence draws on and somewhat reinforces a child/adult dichotomy.
} 
Both Western discourses have been rendered 'global', imbuing activities sponsored by international organisations, but in the 'alternative' model the Western origins are more commonly denied amid claims to universal validity. Dominant understandings of childhood have become accepted as 'common sense' in globalised institutions (Holt and Holloway 2006). This is true of both "northern myths of childhood as a time of play and innocence' (Robson 2004: 227) and more recent celebrations of children's participation (Skelton 2007). This globalisation of notions of appropriate childhoods partly reflects a longstanding interpenetration of theories of child development and notions of foreign underdevelopment (Aitken et al 2007; Gagen 2007). 'Like globalization, the global child is not natural, but contrived from fluid capital processes' (Aitken 200I: 123). In practice, however, Third World countries do not have the resources to deliver the Western ideals of childhood and youth that are being promoted (Ruddick 2003).

\section{Basotho notions of childhood and youth}

If the 'global child' that has been subject to critique is not only Eurocentric, but dynamic and contradictory, there is no reason to presume a singular, essential 'Sesotho childhood'. The Basotho have only identified themselves as a nation since the 1830s, and any notion of 'Sesotho culture' bears a colonial imprint, as well as multiple transformations associated with the subsequent modernisation of southern African society. There are, nonetheless, identifiable distinctions between discourses and practices of childhood in Lesotho and those in Western societies. A prominent feature is the dispersed responsibility for children. Although the nuclear family is not insignificant, extended family and friends and neighbours also play diverse roles in childrearing. Children do not 'belong' strictly to their parents and may be left in the care of neighbours for a few days, or sent to live with relatives or acquaintances for months or years. Even in 1993 (before AIDS took hold) $22.4 \%$ of Lesotho households contained children who were not the offspring of the head of household (UNICEF 1999).

Children in Lesotho are also discursively constructed as capable. One study suggests childhood is considered to end at 10 years of age, with children placed in the care of older sisters to ensure they grow up quickly (Montsi 1978). Children are expected to work as preparation for adulthood (Bissell et al 2000). In the 1996 Census, $8.5 \%$ of children aged 10-14 were economically active and not in school (UNICEF 1999). The 2004 Lesotho Child Labour Study classified 23.3\% of children in Lesotho as child labourers with $5.6 \%$ of 5-9 year olds spending 35 hours or more a week on domestic work (Ministry of Employment and Labour 2004). Domestic duties place girls in close contact with adults, again encouraging their quick acculturation into adult society. About 10\% of 6-15 year old boys are fulltime herdboys, half of them under I 2 (Gill 1994). Herdboys have minimal adult supervision, often spending weeks at distant cattle posts (Bissell et al 2000). Equally, rural children attending secondary school often board in minimally supervised hostels or in rented rooms, looking after themselves, cooking and washing their own clothes (Ansell 1999).

At the same time, children and youth are considered incapable. There is a widespread acceptance, including among young people themselves, of the need for disciplining by adults. Children above the age of seven 
(deemed capable of distinguishing right from wrong), are subject to regular corporal punishment, which many regard as appropriate even in their late teens (Gill 1994). Equally, young people defer to adults when making important decisions. Research in the 1990s found only a minority of caregivers believed children should be permitted to choose their own career path, and even fewer allowed their children to participate in family decisions (Bloem 1998). Two-thirds of the children interviewed thought their parents should assist in choosing their marriage partners, and $48 \%$ agreed with the statement that 'The issue of child rights is a non-African hype' (Bloem 1998: 34). The age of majority in civil law is 18 , but this only applies to limited fields such as voting rights. Many areas of life are governed by customary law, in which adulthood is attained on marriage. However, although a girl becomes a woman when she marries (even before 18), she never attains full majority status, being transferred from her father's to her husband's jurisdiction on marriage (NGO Coalition for the Rights of the Child 2000).

'Traditional' childhood and youth are highly gendered, in ways not dissimilar to those inscribed in Western discourses. There are different duties to fulfil and different characteristics to cultivate. These distinctions dissipate in an ostensibly gender-blind educational system, although in practice schools serve girls very differently from boys, with less positive outcomes for their adult lives (Ansell 2002a). Like both global models, Basotho childhoods are also understood as asexual. In adolescence, families seek to minimise the likelihood that girls, in particular, will engage in premarital sex. Discussion of sexual matters with young people is unusual, although in the past it was the role of aunts and uncles to inform young people about sex.

\section{Addressing AIDS in Lesotho's education sector}

This paper draws on a wider research project examining how Lesotho's education sector is addressing the AIDS pandemic. Interviews were conducted with more than 40 officials working in government, international NGOs, donor agencies, UN agencies, local NGOs and churches, and these were supplemented by analysis of policy documents, reports and publicity materials. Both the interview transcripts and documents were subjected to critical discourse analysis. They were coded manually for a series of concepts deriving from the discursive constructions of childhood and youth outlined above, but also interrogated for indications as to why particular representations were employed and in particular the power relations involved. The analysis of visual imagery followed Rose's (200I) guidelines for exploring visual texts. The paper focuses on three forms of intervention, being implemented in response to the pandemic. All three inscribe particular discursive constructions of childhood and youth, through interaction with discursive framings of AIDS (Craddock 2000). Firstly, bursary schemes are employed to keep orphaned children attending school. These tend to represent orphans as the vulnerable and impoverished face of the epidemic. Secondly, life skills education has been heavily promoted, with a view to turning Lesotho's young people into autonomous agents who are capable individually of protecting themselves against AIDS and dealing with its consequences. Thirdly, youth organisations have been working in Lesotho's schools to address stigma and discrimination, rooting their campaigns in a discourse of rights. All 
three interventions are shown to represent children or youth in hybrid ways that demonstrate a degree of 'local' agency in translating 'global' concepts. Yet all are imbued with unequal power relations and contribute to some degree to an increasing neoliberalism.

\section{Bursary schemes: Vulnerability and poverty}

A number of bursary schemes operate in Lesotho. The Ministry of Education and Training (MOET) introduced the largest scheme in 1999 with funding from the World Bank, initially in response to falling school attendance over the 1990s (attributed to impoverishment associated with the entrenchment of mineworkers). The bursaries were intended to supplement the World Bank free primary education scheme which was introduced incrementally, a year at a time. The Ministry pays fees and for uniforms, books, stationery and examination fees for needy students, up to the third year of secondary school.

The emphasis of the MOET scheme today is firmly on orphans. Eight categories of children are eligible for support (as outlined in the Ministry's brochure):

Who is eligible

- Orphaned child

- Abandoned child

- Child with disability

- Child from a broken family

- Child of parents with low income

- Herd boy

- Servant child

- $\quad$ Street child

As the number of applications for funding exceeds the number that can be supported, applications are ranked by priority according to the Bursaries Office Continuum of need:

\section{Very desperate}

- Child whose parents are deceased

- Abandoned child

- Child with unemployed parent(s)

- Child with disabled parent(s)

- Child with single parent

- Child who comes from a big family

Not so desperate 
Although the two listings do not neatly tally with one another, it is clear that priority is to be given to orphans. Need - specifically the need for material assistance in order to attend school - is associated with parental absence. The continuum of need inscribes assumptions about appropriate childhoods, and the nature of the family that is expected to raise a child. It reflects a Western conception of childhood more than a Basotho one, in which the extended family might figure more prominently. The basis for the continuum is unclear. It is apparently based neither on consultation with potential users of the bursaries (MOET does not consult with children or families ${ }^{5}$ ) nor on the various situation analyses of orphans and vulnerable children (e.g. Kimane 2004; Kimane 2005; MOHSW 200I).

Studies from South Africa have argued that policy discourse there focuses too narrowly on the vulnerabilities of orphans (Henderson 2006), a situation deemed to relate to broader global discourses that associate vulnerability with parental death. In practice, of sub-Saharan Africa's 'orphans', $85 \%$ have a surviving parent (Meintjes and Giese 2006), but this is little recognised. It is widely assumed that 'orphans' remain without adult guidance (Henderson 2006), even among education ministry personnel:

\section{....the bursary provides for the cost of uniforms?}

ya books, uniforms the whole load of the school. Because for an orphan she has nowhere to turn to so we would have to shoulder the whole cost of educating

(Interview with CEO Curriculum Services, Ministry of Education and Training)

Yet this is seldom true even for those who lose both parents. The majority of orphaned children in Lesotho receive care and support from their extended families (Bless 2005; Kimane 2005; Kimaryo et al 2003). Indeed, children's lives in southern Africa are fluid, and there is a normative expectation that children should relate to multiple caregivers over time (Henderson 2006). Children are embedded in communities, and there is good reason to focus on the vulnerability of communities rather than targeting individual children ${ }^{6}$ (Kendall 2008).

Prior to AIDS, many of the children now counted as 'orphans' would not have been categorised - or viewed themselves - in this way (Meintjes and Giese 2006). Local conceptions of orphanhood may focus on 'destitution, alienation and a lack of belongingness' (Henderson 2006: 307), rather than death of parents. Oprhanhood, through association with lack of social support, can be stigmatising (Meintjes and Giese 2006). Yet, some children adopt this globally sanctioned identity for its economic valence (Meintjes and Giese 2006). Such a situation is encouraged by bursary schemes like that in Lesotho.

International concern for orphanhood is partly associated with fear of social breakdown, which is sometimes viewed as an inevitable consequence of the lack of adult guidance that is assumed to follow from

\footnotetext{
${ }^{5}$ Interview with Inspector Development Studies, former focal person for HIVIAIDS, Ministry of Education.

${ }^{6}$ Though see Ansell and Young (2004).
} 
parental death. There is, however, no evidence that orphanhood causes social breakdown, and apocalyptic predictions distract attention from other forms of disadvantage affecting individual children, families and communities (Bray 2003). Orphanhood in itself need not make children vulnerable - outcomes for orphans are mixed, but reflect the social and economic environments in which children become orphaned (Bray 2003). Orphans are a heterogeneous group, and focusing on orphanhood obscures commonalities that orphans share with other children (Henderson 2006) and 'contributes to a one-dimensional view of the impact of the AIDS epidemic on children' (Meintjes and Giese 2006: 408). Deteriorating economic circumstances associated with sickness often have more dramatic practical impacts on young people's lives than parental death (Young and Ansell 2003). Moreover many children live in difficult situations irrespective of parental death (sometimes due to other impacts of AIDS such as the sickness or death of a non-parent breadwinner, or unemployment related to sickness). In 2000, UNICEF switched from referring to 'children orphaned by AIDS' to 'Orphans and (other) Vulnerable Children', yet this has not yet shifted attention 'onto the broader collective of children who are burdened by the social, economic, physical and emotional effects of the pandemic' (Meintjes and Giese 2006: 410).

While children without parents are not always the most needy, the focus of Lesotho's World Bank-funded bursary scheme on orphans may not be entirely unfounded. The education of orphans is sometimes neglected by foster carers, even when funds are available (van Blerk and Ansell 2006). Orphans might also have greater need of schooling, because they lack some of the alternative livelihood opportunities available to other children (Drimie 2003). However, these arguments are not made in order to justify the focus.

What, then, is the basis for the emphasis on parental death it inscribed in the 'continuum of need'? There are several possible explanations. Pragmatically, orphanhood is easily established, in comparison to abandonment or parental unemployment, and is a permanent condition. To assess more general family hardship would be more costly and contentious. Equally, the funding available for AIDS initiatives may be skewing priorities: allocating bursaries to orphans is a simple outlet for such funds. The World Bank may be keen to entrench a particular view of family, but it is more probable that a focus on AIDS orphans represents an avoidance of more politically contentions questions around poverty and its growing prevalence in southern Africa. The 'global orphan' (Meintjes and Giese 2006) portrayed by the 'donormedia complex' (Ennew 2005) offers a relatively comfortable focus for aid work.

It is not only international agencies that focus attention on orphans. Lesotho's Office of the First Lady (OFL) was formed in 200 I with a mandate to provide care and support to orphans and vulnerable children (OVCs). It established a scheme to return OVCs to school by paying for fees, uniforms and other necessities. MPs' spouses solicit applications from OVCs through local chiefs in the constituencies. Applicants are then randomly selected for 'adoption' by private sponsors, sought through overseas embassies. Individuals or organisations generally 'adopt' children until they attain a certain level of education or reach a certain age. In some cases entire families are adopted. 
Child sponsorship schemes are widely criticised for representing African children as in need of rescuing, thereby maintaining patronising colonial relations (Burman 1992). The adoption of this approach by a branch of government is perhaps surprising. Unlike the Ministry of Education / World Bank scheme, the OFL policy did not involve international agencies directly in its drafting. Nonetheless, the scheme relies on appealing to overseas donors.

Is it not only official channels that promote a view of orphans as victims due to lack of parents. The emphasis on orphans as destitute victims is repeated through other school-based initiatives. A booklet for the LIVE and let LIVE competition, distributed in Lesotho schools, speaks of orphans living 'in abject poverty' and depicts two children, utterly isolated, in an empty earth-floored room, asking 'What is life after the passing away of the parents?'. Such representations of the 'decontextualised child (wide-eyed and staring at the camera) who, seemingly, can be helped only by the viewer' (Aitken et al 2007: 8) were used prolifically in the past for fund raising by international NGOs, but were widely condemned for suggesting dependence on donors and denying the social relationships which even very poor or orphaned children enjoy (Burman 1992). Very few children are left to fend for themselves unsupported, and representing them in this way pathologises their families and cultures, indicting them for failing to care (Burman 1992). The fact that both children depicted are girls is typical of the images used to signify childhood vulnerability (Burman 2008), and both draws on and reinforces Western representations of femininity, as well as a wider gendering of the epidemic as female (Faria 2008).

Yet in this case the representation comes not from a Western or international organisation; indeed, many international organisations now have guidelines on the use of photographs to avoid negative imagery (see, for example, Save the Children 1995). The competition was organised by Positive Action, a Lesotho-based NGO, founded by a German, who subsequently withdrew from the organisation. Positive Action aims to be independent of major donors, and supports its work through income generation projects and private sector donations. The booklet was produced with funding from the Ministry of Agriculture, Radio Lesotho, the Ministry of Health, District AIDS Task Forces, TEBA, Lesotho Planned Parenthood Association, Positive Health, and numerous private sponsors.

Below the photograph, the reader is told: 'We all have to care for the thousands of orphans in the country. They are our future! Care for them they will care for you. Neglect them and they will steal from you'. It is difficult to imagine these sentiments expressed publicly by an international NGO. But perhaps it is from a Western perspective, based on assumptions that children are essentially innocent, that these statements are problematic. The booklet targets people in AIDS-affected communities in Lesotho, more than potential donors (although the sponsors doubtless have expectations). Juxtaposed with the photograph, this calls not for a 'child-saving' mission by well-meaning outsiders, but for a collective acknowledgement that 'they are our future'. The threat 'they will steal from you' is perhaps less a Dionysian reference to the demon within 
children, than a reminder that communities bear the consequences of their collective deeds and omissions, and that the intergenerational contract remains crucial to the sustenance of families and communities.

In sum then, bursary schemes and other orphan-related initiatives in schools emphasise destitution faced by orphans, who are portrayed as vulnerable due to the absence of (functioning) families that would normally cater for their needs. Interventions are developed by different organisations, local and global, and by different personnel with their own motives and drawing on different discourses (though as Burman (2008: 54) points out, 'professionals drawing on dominant discourses of childhood are not necessarily uncritical subscribers to it'). Yet ultimately, 'orphans remain the recipients of an abundance of tragic imagining' (Meintjes and Giese 2006: 4I0). Henderson (2006: 306) sums up the situation thus: 'Textures of lightness, beauty, love, strength and conviviality - often equally present in social contexts of scarcity and pain - are excluded from analysis in an attempt to depict the epidemic's gravity'. Despite the diverse discursive roots of this apparently hybrid imagery, its effect is to point to AIDS as the fundamental social concern: a message that is more congenial to the Western-based funders and NGOs that exercise the power to allocate funds than structural explanations of poverty and disadvantage. Children are rendered individualised victims requiring direct external intervention in the interests of their present and future lives. The representations produced 'on the ground' in Lesotho serve the neoliberal agenda promulgated by the West irrespective of the perspectives of those involved. Their production does not always implicate Western actors directly, but it allows Western power to be exercised internationally in subtle, indirect and complex ways.

\section{Life skills education}

Life skills programmes are now widespread across Africa (Boler and Aggleton 2005; James et al 2006; Magnani et al 2005; Visser 2005). In Lesotho, they have been introduced by UNICEF, Peace Corps and the Lesotho Association of Teachers. ${ }^{7}$ At face value, they differ greatly from the inculcation of fact-based imported knowledge that imbues the formal school curriculum (Ansell 2002b). Teachers are intended to follow the instructions in lifeskills manuals to impart, for instance, communication, decision-making, thinking, relationship and emotion management skills, through techniques such as role play, forum theatre, games, puzzles and group discussions (Peace Corps 2000). These skills are seen as necessary precursors to behaviour change.

young people are infected because they are sexually active with no life skills and education ... they have seen people dying from HIV and related diseases, but then there are still more and more people getting affected so what could be the solution? I think life skills to help people change their behaviour.'

(Interview with life skills coordinator, Lesotho Association of Teachers)

\footnotetext{
${ }^{7}$ Though each draws on other sources. The Peace Corps (2000) manual, for instance, credits materials created by WHO; UNESCO; ActionAid; CDU, Ministry of Education, Zimbabwe; UNICEF, Harare.
} 
The programmes are also intended to address the needs of orphans who are believed to be missing out on the lifeskills they would 'normally' have acquired through their families. They are further seen as a way of tackling stigmatisation of AIDS. Lifeskills education has become the intervention of choice for many international organisations keen to promote prevention ${ }^{8}$ and also to be seen to address the needs of AIDSaffected children. Access to lifeskills education is now reported biennially in the UNAIDS Report on the Global AIDS Epidemic. This, then, is truly a global regime with enforcement secured through international surveillance.

The process of introducing lifeskills into schools is not, however, monolithic or simply unidirectional, as suggested in the following interview extract about a programme training teachers in lifeskills:

\section{Did they (Education International) initiate this?}

Partly yes, but on the other hand it's like the LAT have been looking for ways of doing it, it met right in the centre. We were looking at ways of doing it as well ... we are using a manual from Education International and the WHO.

\section{I was shown something similar from Peace Corps, a lifeskills manual.}

Yes it would be similar but this one is from Education International, WHO have a lot to do with both, they are like, it's for the world. It's global. They run a programme in nine countries.

(Interview with lifeskills coordinator, Lesotho Association of Teachers)

The lifeskills coordinator had in fact been trained in lifeskills by Peace Corps and, having gained experience training Peace Corps Volunteers, was seconded into his current job by the government. Thus ideas from WHO, Brussels-based El and US government agency Peace Corps, came together under the guise of a Lesotho-based teachers' union.

UNICEF, too, is promoting lifeskills education, working with the government, but not operating through the National Curriculum Development Council (NCDC), that normally undertakes curricular development. While lifeskills will be incorporated into health education, their introduction is considered too urgent for the usual consultative process. Nonetheless, NCDC employees rationalise the programme, not as an external imposition, but as a culturally appropriate response to social change.

'... it's not very easy honestly, to try to do things and do them in the context of Lesotho, but here from the curriculum development the idea will be you know, like the life skills, something that has always been there ... it's not very different from what we have been doing in our culture, but you know, we used to have, you know, structures independently who would give advice to young people, but the because of some changes the

\footnotetext{
${ }^{8}$ Evidence on the efficacy of life skills programmes in altering behaviour is unclear (James et al 2006; Magnani et al 2005; Visser 2005).
} 
structures are no longer there, therefore education has to play some role there, and now it has to be done by teachers'

(Interview with Health and PE Curriculum Advisor, NCDC)

Not only does the rhetoric of urgency allow international agencies to intervene in national processes, and the state to intervene in fulfilling what was previously a family or community role, but this is achieved in part through promulgating a belief that families and communities are failing to function in the context of AIDS. This echoes the discourse that permeates bursary schemes.

Lifeskills programmes are also made more palatable through their blandness. Because they are relatively non-prescriptive of precise content, they may be interpreted and even moulded to suit different interpretations of childhood. In particular, the extent to which they are envisaged to incorporate explicit learning about sex varies significantly. While in policy circles, as the interview extract below suggests, lifeskills education is assumed to address young people's sexuality, the hollow concept ensures compatibility with a view that intergenerational discussion of sex is inappropriate, or provides opportunities for myriad different messages.

'they know if all the options have failed and they want to practice sex the option is condom so they have to know how to use a condom. Thirteen, fourteen, fifteen, they are provided with that knowledge, so they have life skills'

(Interview with Chief Health Educator, Ministry of Health and Social Welfare)

The wider world in which young people live is barely acknowledged in lifeskills programmes, nor are differences of culture and class, and the structural constraints on life chances. Even gender receives little attention - with the exception of the interview extract below, gender differences were scarcely mentioned by those interviewed, even though gender is addressed in the lifeskills manuals. As with education more generally in Lesotho, there appears to be an assumption that the programmes are gender neutral, despite an underlying sense that the imagined beneficiary is female, in line with the broader female gendering of AIDS (Faria 2008).

Boler and Aggleton (2005) are critical of the individualistic approach of lifeskills education - the emphasis on autonomy and self-empowerment neglects political, economic and cultural constraints. As Boler and Aggleton (2005) observe, 'Young people do not live in a vacuum divorced from the world outside, nor are they socialised in such: they develop complex strategies to deal with the complex social structures in which they live'. These strategies are not addressed. In an African setting, individual self-identity is strongly incorporated within wider relationships, particularly with family and community. Yet the notion of individual self-empowerment is embraced by many Basotho involved in education, albeit in somewhat ambivalent terms: 
'we make them understand that they have got to stand on their own two feet they have got to say no to sex, it's not about using condoms and things it's about valuing their own, loving and valuing their own lives and how do we help them to do that, we have got to give them the necessary life skills ... especially for girls to be assertive to know what they want and to go for what they want ...'

(Interview with Inspector, Primary Services, Ministry of Education)

Despite the rhetoric of individualism and empowerment, lifeskills are represented here in an instrumentalist way (moreso than among international advocates of the programmes). It is assumed that once girls "know what they want', this will not be sex. While lifeskills education may have gained resonance locally, it still serves an 'international' neoliberal agenda: both moulding individualised agency and driving towards an outcome target. Indeed, the reinterpretations made by Basotho in positions of authority render the programmes more compatible with local conceptualisations of childhood, and thus more likely to be implemented: even if the extent to which they address young people's sexuality is limited, they serve to encourage young people to aspire to individual autonomy. Thus the hybridisation of the programmes serves the exercise of Western power.

\section{Youth organisations: emphasising rights}

The third form of intervention considered here is the promotion of the rights of young people infected or affected by AIDS undertaken by youth organisations in Lesotho.

'We are currently developing a programme on children orphaned through HIVIAIDS and how to conscientise the community about the rights of young people unfortunately living with the stigma of HIVIAIDS ... We have given it the perspective of rights of victims of AIDS - both orphans and those [in]fected'

(Interview with Lesotho Youth Federation)

Representatives of several youth organisations stressed that AIDS awareness initiatives had effectively informed children about avoiding infection, and they wished instead to focus on those already affected, and specifically their rights.

The youth organisations are relatively responsive to grassroots views compared with more formal NGOs. The Lesotho Youth Federation representatives insisted that 'all of our projects have been constructed out of realised problems' (Interview, LYF). Their ideas are informed by members' observations of needs, and through workshops that bring in students from schools nationwide. Yet the way in which these observations are framed and responded to is not unmediated. They speak of the 'exclusions of children and stigmatisation of HIVIAIDS'; 'if both parents die, guardians [usually] misuse such children, such that they don't have their rights ... Our focus is rights' (Interview, LYF). Observations are framed explicitly through the lens of 
rights, which is prominent among youth organisations in Africa, supported by declarations at the UN (United Nations 200I), and resonates with the discourse of AIDS activists (Seidel I993).

It is noteworthy that LYF's autonomy is not unqualified. It engages with youth organisations in other countries, and its projects depend on funding, often from non-local sources. Projects are developed and proposals submitted to foreign embassies. The Ministry of Health has provided some assistance. One proposal focusing on the rights of AIDS-affected children was submitted to the Firelight Foundation, a private charitable foundation founded in the US in 1999, whose website declares:

'The mission of the Firelight Foundation is to support and advocate for the needs and rights of children who are orphaned or affected by HIVIAIDS in Sub-Saharan Africa. Firelight strives to increase the resources available to grassroots organizations that are strengthening the capacity of families and communities to care for children made vulnerable by HIVIAIDS' (Firelight Foundation 2008)

The availability of funding in this area may contribute to the discursive construction of AIDS-affected children in Lesotho.

The discourse of rights is a seemingly more constructive way of conceptualising AIDS-affected children than the emphasis on destitution and victimhood that informs bursary schemes. However, as discussed above, the rights discourse is frequently accused of Eurocentrism, and a focus on the individual that conflicts with fundamental values of African societies. It is widely suggested that the Global rhetoric of children's rights glosses over located young people, suggesting simple progress towards development (Kjorholt 2007).

However, the LYF elected to deploy the discourse of rights in particular ways, whether in line with its own beliefs or because it assumed this would improve its funding prospects. Although the LYF expressed concern with promoting children's rights and was working with young people, it was notably more concerned with making communities aware of children's rights than assisting young people to assert their rights. The concern was more about collective responsibility than individual claims, even expressed through the language of rights. Reynolds et al (2006) outline how proponents of rights protocols consider them powerful tools for challenging existing power relations; opponents believe they are only useful to already powerful groups, and necessarily reproduce inequality; while radical critics see them as ideological constructs that serve a Western agenda. Yet they insist that all of these perspectives are too simplistic. 'Rights are brought into effect through social practices in particular contexts and time frames, and do not necessarily always carry the same meaning, nor do the consequences of particular usages of children's rights necessarily coincide with their initial objectives' (Reynolds et al 2006: 294). This ties in with Burman's (2008: 5) view that 'the Convention is ultimately a legal instrument rather than a theoretical statement about children and childhood. This means that it demands of its practitioners the continuous work of 
interpretation and translation into specific contexts and moments'. Thus the use to which LYF puts the discourse of rights should not be assumed, de facto, to serve neoliberal interests.

The interventions supported by youth organisations, like those outlined in the previous sections, are hybrid outcomes of relationships between organisations and personnel, and do not reflect singular Western or local discourses of childhood or youth, but rather loosely determined hybrid discourses. Nonetheless, while they may reinterpret or distort seemingly monolithic Western agendas, they ultimately tend to support a broader trend towards neoliberal modes of personal governance.

\section{Conclusions}

This paper has shown how initiatives responding to AIDS through Lesotho's education sector have characterised AIDS-affected young people in diverse ways: as vulnerable parentless victims; as requiring skills for individual self-empowerment; and as subjects of rights (for others to enact). While all these discursive framings draw on Western notions, they are not simply external impositions. Rather, their mobilisation reflects the interests of combinations of national and international actors, exercised through individual personnel and often sizeable funding streams.

Undoubtedly the discourses that inform responses to AIDS are substantially shaped by an international politics of funding for AIDS that privileges certain kinds of intervention (Faria 2008). Use of 'standardized bureaucratic language' can obstruct meaningful insight (Reynolds et al 2006: 296), and imported knowledge is often taken for granted and acts to sideline local understandings in the development of interventions (Henderson 2006). Where funding is large and deployed through major agencies and there is an apparent imperative to act with urgency, there is limited scope for national government or local agencies to shape interventions in ways that reflect more clearly local understandings of childhood and youth:

'if somebody out there sees that we need that as an emergency, we just have to do it ... we really can't have much control on the when to that, because when the donors come and say we wanted to do this ... we are now part of the global village, if we try to internalise them, say looking this in the Lesotho context, maybe we find that we are, time wasted away ... it is good to sometimes to say 'in our context' but sometimes there are some things which you have to act quickly'

(Interview with Health and PE Curriculum Advisor, NCDC)

International donors are clearly influential, and do have specific interests that they pursue. Yet the interplay between global discourses on children and local and national concepts is not simply about the direct power of northern institutions (Burman 2008; Kjorholt 2007). Global discourses can be used effectively in defence of local interests. Research by Seidel (1993) demonstrates how Africans have understood and discussed AIDS in multiple and competing ways, developing discourses of rights and empowerment in resistance to medico-moral discourses of control and exclusion; yet neither rights nor empowerment is an 'authentically' 
African discourse. Moreover, there are clear dangers in venerating local discourses: treating childhood as locally defined actually draws attention from wider global power inequalities and may cast blame for difficulties on individuals (Burman 1996). Furthermore, "local, culturally specific understandings of childhood also need to be theorised and deconstructed' (Kesby et al 2006: 185).

The material presented above destablises any simple distinction between local and global discourses of childhood or youth. Such dichotomisation is problematic and unhelpful (see Aitken et al 2007; Ansell 2009). As Burman (1996: 48) points out, '[w]hatever the western origins or assumptions guiding local (educational or welfare) practices, these ideas have now entered into previously non-western contexts to accord them new sets of local meanings ... [They] are now structured into state educational and professional structures such that these precepts may have acquired 'indigenous' status'. Policy dialogue in Lesotho brings together people from Western countries, other African countries and Lesotho itself, along with ideas filtered through literature produced by UN agencies in the production of interventions. While the discourses that infuse representations of children in education sector AIDS interventions in Lesotho may be identifiably global, they are not simply global. They are transformed in the locality, albeit through power-laden relationships.

Tracing the production of hybrid discourses and their effects is an important task, and understanding this offers the potential to contribute to new constructions of childhood and youth, as Ruddick (2003: 357) points out:

'What is needed now is not a retreat into cultural relativism or the introduction of singular universal norms, forms or standards to which all must aspire, but rather the patient construction of more consistent and persistent connections. This is not an imposed ideal vision of the First World on the Third World, but an establishment of mutual and myriad connections that take into account varied contexts and resources.

Far from being extraneous to or even a byproduct of global transformations, these conflicts and rerepresentations of the nature of youth and childhood are at the very center of the struggle over hearts, minds and bodies in the emergence of a new globalized modernity'.

Even where connections do 'take into account varied contexts' it is crucial to remain aware of power relations. Cultural material circulates across national boundaries in varied ways, some of which maintain particular cultural-political interests. It is important to trace these circulations, to understand how they support different interests. Dominant discourses, even when translated by national institutions and infusing local interventions, are power-laden. Irrespective of the motivations of local actors, the representations of young people produced and circulated through transnational connections in relation to AIDS have the capacity to serve neoliberal agendas. It is thus noteworthy that the inability to characterise interventions as 
simply local or global does not negate the power relations through which they are produced or prevent them from serving particular ends.

\section{Acknowledgements}

The author gratefully acknowledges the support of an RGS-IBG small grant, provided by Mrs. Pamela Savage, for the wider research project on which this paper is based. Thanks are also due to the individuals who gave their time to be interviewed, and three anonymous reviewers who provided helpful comments.

\section{References}

Aitken S, Lopez Estrada S, Jennings J and Aguirre L M 2006 'Reproducing life and labor: global processes and working children in Tijuana, Mexico' Childhood I3(3), 365-387

Aitken S C 200I 'Global crises of childhood: rights, justice and the unchildlike child' Area 33(2), I I9- I 27

Aitken S C, Lund R and Kjorholt A T 2007 'Why children? Why now?' Children's Geographies 5(I-2), 3-I4

Ansell N 1999 Southern African secondary schools: places of empowerment for rural girls? PhD Thesis, Keele University

Ansell N, 2002a, "'Of course we must be equal, but ...': imagining gendered futures in two rural southern African secondary schools" Geoforum 33 179-194

Ansell N 2002b 'Secondary education reform in Lesotho and Zimbabwe and the needs of rural girls: pronouncements, policy and practice' Comparative Education 38(I), $91-1 / 2$

Ansell N 2009 'Childhood and the politics of scale: descaling children's geographies?' Progress in Human Geography 32(2) 190-209

Ansell N 2009 'Producing interventions for AIDS-affected young people in Lesotho's schools: scalar relations and power differentials' Geoforum 40(4), 675-685

Ansell N and van Blerk L 2004 'Children's migration as a household/family strategy: coping with AIDS in Malawi and Lesotho' Journal of Southern African Studies 30(3), 673-690

Ansell $N$ and Young L 2004 'Enabling households to support successful migration of AIDS orphans in southern Africa' AIDS Care I6(I), 3-10

Bissell S L, Kimane I and Mturi A J 2000 Rapidly assessing children at work in Lesotho: Volume I: Context and overview of findings, Draft 7, NUL in collaboration with UNICEF

Bless B D 2005 'Challenges and livelihood strategies of girls and boys in child-headed households in Maseru, Lesotho' in Schlyter A (ed) Gender, generations and urban living conditions in southern Africa ISAS, Roma

Bloem J 1998 Basotho practices on caring for children and women in Lesotho, Sechaba Consultants for UNICEF, Maseru

Boler T and Aggleton P 2005 Life skills-based education for HIV prevention: a critical analysis, Save the Children and ActionAid International, London

Bowlby J 1966/I95 I Maternal care and mental health Schocken, New York 
Boyden J 1990 'Childhood and the policy makers: a comparative perspective on the globalization of childhood' in James A and Prout A (eds) Constructing and reconstructing childhood Falmer, London, Pp. $184-215$

Boyden J and Ennew J 1997 Children in focus: a manual for participatory research with children Radda Barnen, Stockholm

Bray R 2003 'Predicting the social consequences of orphanhood in South Africa' African Journal of AIDS Research 2(I), 39-55

Burman E 1992 'Innocents abroad: Western fantasies of childhood and the iconography of emergencies' Disasters 18(3), 238-253

Burman E 1995 'The abnormal distribution of development: policies for Southern women and children' Gender, Place and Culture 2(I), 2I-36

Burman E 1996 'Local, global or globalized? Child development and international child rights legislation' Childhood 3, 45-66

Burman E 2008 Developments: child, image, nation Routledge, London

Caputo V 1995 'Anthropology's silent 'others': a consideration of some conceptual and methodological issues for the study of youth and children's cultures' in Amit-Talai $V$ and Wulff $H$ (eds) Youth cultures: a cross-cultural perspective Routledge, London, pp. 19-42

Craddock S 2000 'Disease, social identity, and risk: rethinking the geography of AIDS' Transactions of the Institute of British Geographers 25(2), 153-168

Drimie S 2003 'HIVIAIDS and land: case studies from Kenya, Lesotho and South Africa' Development Southern Africa 20(5), 647-658

Ennew J 1995 'Outside childhood: street children's rights' in Franklin B (ed) The handbook of children's rights: comparative policy and practice Routledge, London, pp. 20I-2I5

Ennew J 2005 'Prisoners of childhood: orphans and economic dependency' in Qvortrup J (ed) Studies of modern childhood: society, agency and culture Palgrave, London I28-I46

Faria C 2008 'Privileging prevention, gendering responsibility: an analysis of the Ghanaian campaign against HIV/AIDS' Social and Cultural Geography 9(I), 4I-73

Finn J L 200I 'Text and turbulence: representing adolescence as pathology in the human services' Childhood $8(2),|67-| 9 \mid$

Firelight Foundation 2008 'Apply for a grant', accessed 20th March 2008, http://www.firelightfoundation.org/apply.htm

Gagen E 2007 'Reflections of primitivism: development, progress and civilization in imperial America, I8981914' Children's Geographies 5(I-2), I5-28

Gill D (ed), 1994 The situation of children and women in Lesotho. Sechaba Consultants for the Ministry of Planning, Economics and Manpower Development, financed by UNICEF, Maseru, Lesotho

Griesel R D, Swart-Kruger J and Chawla L 2002 "Children in South Africa can make a difference': an assessment of 'Growing Up in Cities' in Johannesburg' Childhood 9(I), 83-I00 
Griffin C 200I 'Imagining new narratives of youth: youth research, the 'new Europe' and global youth culture' Childhood 8(2), I47-166

Henderson P C 2006 'South African AIDS orphans: examining assumptions around vulnerability from the perspective of rural children and youth' Childhood I3(3), 303-327

Heywood C 200I A history of childhood: children and childhood in the West from medieval to modern times Polity, Cambridge

Holloway S L and Valentine G 2000 'Spatiality and the new social studies of childhood' Sociology 34(4), 763783

Holt L and Holloway S L 2006 'Editorial: Theorising other childhoods in a globalised world' Children's Geographies 4(2), I35- I 42

James A, Jenks C and Prout A 1998 Theorising childhood Teachers College Press, New York

James S, Reddy P, Ruiter R A C, McCauley A and Van Den Borne B 2006 'The impact of an HIV and AIDS life skills program on secondary school students in Kwazulu-Natal, South Africa' AIDS Education and Prevention I8(4), 28I-294

Jenks C 1996 Childhood Routledge, London

Jones O 1999 'Tomboy tales: The rural, nature and the gender of childhood' Gender, Place and Culture 6(2) $117-136$

Kendall N 2008 "Vulnerability' in AIDS-affected states: rethinking child rights, educational institutions, and development paradigms' International Journal of Educational Development 28(4), 365-383

Kesby M, Gwanzura-Ottemoller F and Chizororo M 2006 'Thorising other, 'other childhoods': issues emerging from work on HIV in urban and rural Zimbabwe' Children's Geographies 4(2), I85-202

Kimane I 2004 Situational analysis of orphans and vulnerable children in Lesotho, Lesotho Save the Children/UNICEF, Maseru

Kimane I 2005 Update on the situation analysis of orphaned and vulnerable children in Lesotho, Ministry of Health and Social Welfare, Lesotho Save the Children and UNICEF, Maseru

Kimaryo S S, Okpaku J O, Githuku-Shongwe A and Feeney J 2003 Turning a crisis into an opportunity: strategies for scaling up the national response to the HIVIAIDS pandemic in Lesotho Third Press, Maseru

Kjorholt A T 2007 'Childhood as a symbolic space: searching for authentic voices in the era of globalisation' Children's Geographies 5(I-2), 29-42

Magnani R et al 2005 'The impact of life skills education on adolescent sexual risk behaviors in KwaZuluNatal, South Africa' Journal of Adolescent Health 36(4), 289-304

Mayo M 200I 'Children's and young people's participation in development in the South and urban regeneration in the North' Progress in Development Studies I(4), 279-293

Mead M 1928 Coming of age in Samoa: a study of adolescence and sex in primitive societies Cape, London Meintjes H and Giese S 2006 'Spinning the epidemic: the making of mythologies of orphanhood in the context of AIDS' Childhood I3(3), 407-430

Ministry of Education and Training 2005 Education Sector Strategic Plan 2005-20I5 Government of Lesotho, Maseru 
MOHSW 200I The problems of orphans in Lesotho, Ntlafalang Consultants for Ministry of Health and Social

Welfare, Maseru

Montsi M R I 978 A study of the self-concept of Basotho male and female adolescents in secondary schools.

DEd Thesis, University of Massachusetts

NGO Coalition for the Rights of the Child 2000 Complementary report on the implementation of the UN Convention on the Rights of the Child in Lesotho, Save the Children UK, Maseru

Ntozi J P M 1997 'Effect of AIDS on children: the problem of orphans in Uganda' Health Transition Review 7(supplement), 23-40

Pain R 2004 'Introduction: children at risk?' Children's Geographies 2(I), 65-67

Peace Corps 2000 Life Skills Manual Peace Corps Centre for Field Assistance and Applied Research, Washington DC

Piaget J 1972 The principles of genetic epistemology Routledge and Kegan Paul, London

Prout A 2005 The future of childhood RoutledgeFalmer, Abingdon

Prout A and James A 1990 'A new paradigm for the sociology of childhood? Provenance, promise and problems' in James A and Prout A (eds) Constructing and reconstructing childhood Falmer, London, pp. 7-34

Qvortrup J 2005 'Varieties of childhood' in Qvortrup J (ed) Studies in modern childhood: society, agency, culture Palgrave Macmillan, pp. I-20

Reynolds P, Nieuwenhuys O and Hanson K 2006 'Refractions of children's rights in development practice: a view from anthropology - introduction' Childhood I3(3), 29I-302

Robson E 2004 'Hidden child workers: young carers in Zimbabwe' Antipode 36(2), 227-248

Robson E, Ansell N, Huber U, Gould W and van Blerk L 2006 'Young caregivers in the context of the HIVIAIDS pandemic in sub-Saharan Africa' Population, Space and Place I2(2), 93-I I I

Rose G 200I Visual Methodologies: An Introduction to the Interpretation of Visual Materials Sage, London

Ruddick S 2003 'The politics of aging: globalization and the restructuring of youth and childhood' Antipode 35(2), 334-362

Ruddick S 2007 'At the horizons of the subject: neo-liberalism, neo-conservatism and the rights of the child.

Part One: From 'knowing' fetus to 'confused' child' Gender, Place and Culture I4(5), 513-526

Rutter M (1972) Maternal deprivation reassessed Penguin, Harmondsworth

Save the Children 1995 Focus on images, London

Scheper-Hughes N and Sargent C 1998 'Introduction: the cultural politics of childhood' in Scheper-Hughes $\mathrm{N}$ and Sargent $\mathrm{C}$ (eds) Small wars: the cultural politics of childhood University of California Press, Berkeley, pp. I-33

Seidel G 1993 'The competing discourses of HIV/AIDS in sub-Saharan Africa: discourses of rights and empowerment and discourses of control and exclusion' Social Science and Medicine 36, 175-194 Skelton T 2007 'Children, young people, UNICEF and participation' Children's Geographies 5(I-2), I65-I8I Smith P K and Cowie H 1988 Understanding children's development Blackwell, Oxford UNAIDS 2008 Report on the global AIDS epidemic UNAIDS, Geneva 
UNAIDS/UNICEF/USAID 2004 Children on the brink: a joint report of new orphan estimates and a framework for action, New York

UNESCO 2008 'Beyond 20/20 WDS', accessed 19th March 2008, http://stats.uis.unesco.org/unesco/TableViewer/tableView.aspx

UNICEF 1999 Building systems of protection for children affected by HIVIAIDS in Lesotho: report of an assessment of programming in Lesotho for families and children affected by HIVIAIDS, Draft, UNICEF

United Nations 200I Dakar Youth Empowerment Strategy, A/c.3/56/2, United Nations General Assembly, New York

van Blerk L and Ansell N 2006 'Children's experiences of migration: moving in the wake of AIDS in southern Africa' Environment and Planning D: Society and Space 24, 449-47I

Visser M 2005 'Life skills training as HIVIAIDS preventive strategy in secondary schools: evaluation of a large-scale implementation process' Journal of Social Aspects of HIVIAIDS Research Alliance 2(I), 203216

Vygotsky L S 1933/I 967 'Play and its role in the mental development of the child' Soviet Psychology 5(3), 6-I8

Witter S and Were B 2004 'Breaking the silence: using memory books as a counselling and successionplanning tool with AIDS-affected households in Uganda' African Journal of AIDS Research 3(2), I39143

Young L and Ansell N 2003 'Fluid households, complex families: the impacts of children's migration as a response to HIVIAIDS in southern Africa' Professional Geographer 55(4), 464-479 